\title{
Optimization of Process Parameters of Powder Mixed Dielectric EDM for MRR and Ra by Grey Relational Analysis Method
}

\author{
M. S. Bembde ${ }^{1}$, J. K. Sawale ${ }^{2}$ \\ ${ }^{1}$ P.G .Student, Department of Mechanical Engineering, M.G.M"es College of Engineering, Nanded, Maharashtra, India \\ ${ }^{2}$ Professor, Department of Mechanical Engineering, MGM. “s College of Engineering, Nanded, Maharashtra, India
}

\begin{abstract}
Powder mixed electric discharge machining (PMEDM) is a recent innovation for enhancing the capabilities of electrical discharge machining process. The objective of present study is to realize the potential of silicon powder as additive in enhancing machining capabilities of PMEDM. Taguchi methodology has been adopted to plan and analyze the experimental results. L16 Orthogonal Array has been selected to conduct experiments. Peak current, Pulse on time, pulse off time, voltage, and concentration of fine silicon powder added into the dielectric fluid were chosen as input process variables to study performance in terms of material removal rate surface roughness. The grey relational analysis method is used to obtain the common optimum values for MRR and Ra.
\end{abstract}

Keywords: Electrical discharge machining, Machining rate, Spark gap, Silicon powder concentration, Taguchi methodology

\section{Introduction}

Electric discharge machining is a thermo-electric nontraditional machining process. Material is removed from the work piece through localized melting and vaporization of material. Electric sparks are generated between two electrodes when the electrodes are held at a small distance from each other in a dielectric medium and a high potential difference is applied across them. Localized regions of high temperatures are formed due to the sparks occurring between the two electrode surfaces. Work piece material in this localized zone melts and vaporizes.

\section{Principle of PMEDM}

The schematic of a PMEDM machine tool is shown in Figure.

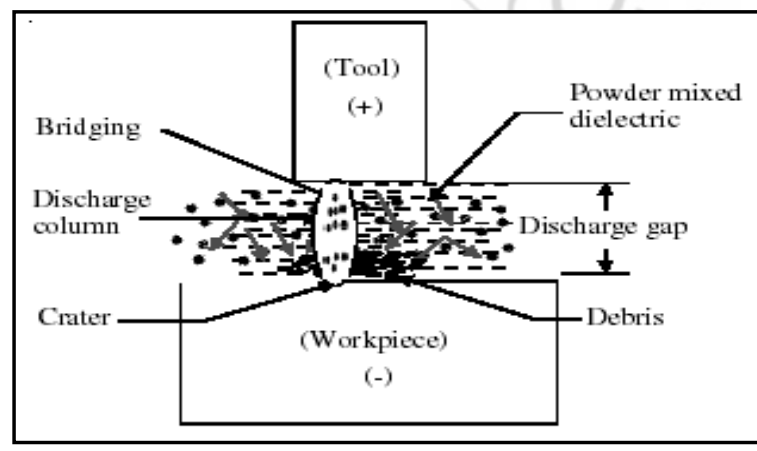

Figure 1: Principle of PMEDM Process.
In this process, the material in powder form is mixed into the dielectric fluid either in the same tank or in a separate tank. When a voltage of $80-320 \mathrm{~V}$ is applied to both the electrodes, an electric field in the range 105 to $107 \mathrm{~V} / \mathrm{m}$ is created. The spark gap is filled up with additive particles, and the gap distance between tool and the work piece increases from $25 \mu \mathrm{m}$ to $50 \mu \mathrm{m}$ to many times larger. Under the influence of electric forces, the powder particles arrange themselves in the form of chainsat different places under the sparking area. The chain formation helps in bridging the gap between both the electrodes. Due to the bridging effect, the gap voltage and insulating strength of the dielectric fluid decreases. The easy short-circuit takes place, which causes early explosion in the gap. As a result, the ,series discharge starts under the electrode area. Due to the increase in the frequency of discharging, the faster sparking within a discharge takes place, which causes faster erosion from the work piece surface.

\section{Experimental Set Up}

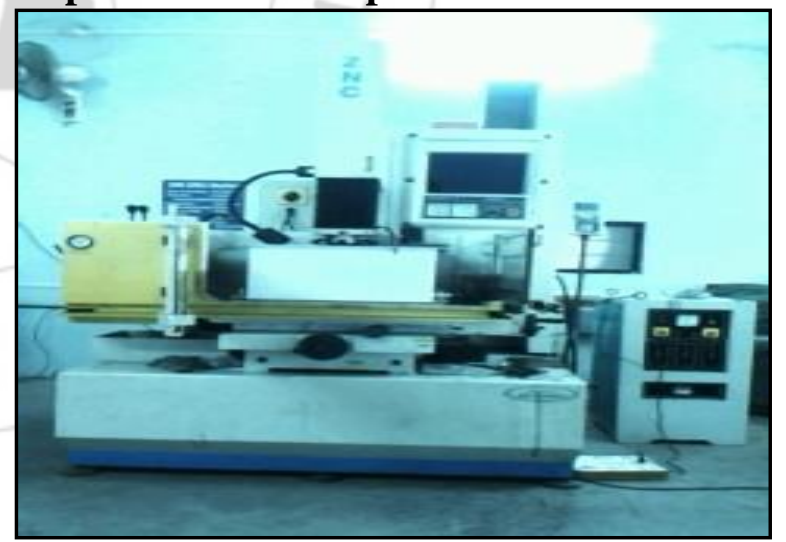

Figure 2: Powder mixed Electric discharge machining (PMEDM).

The various input parameters and output parameters (response variables) selected for the experimentation are as follows:

1) Input parameters

1 Discharge current (Ip)

2 Spark on time ( Ton)

3 Spark off time (Toff)

4 Gap voltage (volt)

5 Concentration of dielectric $(\mathrm{C})$

2) Output parameters

1 Material removal rate(MRR)

2 Surface Roughness ( Ra) 


\section{International Journal of Science and Research (IJSR) \\ ISSN (Online): 2319-7064}

Index Copernicus Value (2013): 6.14 | Impact Factor (2015): 6.391

Silicon powder- The grain size of silicon powder is 15 microns, grade 180

Tool selection-The selected tool is of pure copper. The length of the tool is $80 \mathrm{~mm}$ and diameter of tool is $20 \mathrm{~mm}$. In most of the industries for EDM, the tool used is of copper material. Since copper is cheap as compared to graphite and readily available in the market.

Work piece selection- Material EN31

EN31 is a popular grade of through-hardening alloy steel. EN31 is used in components such as gears, shafts, studs and bolts. EN24T can be further surface-hardened to create components with enhanced wear resistance by induction or nitriding processing. The dimensions of selected work piece are $75 \times 25 \times 6 \mathrm{~mm}$.

Dielectric (EDM oil) - The dielectric used in my experimentation work is EDM oil. The concentration of this dielectric is varied by adding silicon powder. This affects the material removal rate and surface finish.

\section{Experimental Results}

Table 1: Experimental results for Material removal rate and Ra for Material EN31

\begin{tabular}{|c|c|c|c|c|c|c|c|}
\hline $\begin{array}{c}\text { Exp } \\
\text { No }\end{array}$ & $\begin{array}{c}\text { Ip } \\
(A)\end{array}$ & $\begin{array}{c}\text { Ton } \\
(\mu s)\end{array}$ & $\begin{array}{c}\text { Toff } \\
(\mu s)\end{array}$ & $\begin{array}{c}\text { Volt } \\
\text { volt }\end{array}$ & $\begin{array}{c}\text { Conc } \\
\text { g/lit }\end{array}$ & $\begin{array}{c}\text { MRR } \\
\mathrm{mm}^{3} / \mathrm{mim}\end{array}$ & $\begin{array}{c}\text { Ra } \\
\text { um }\end{array}$ \\
\hline 1 & 3 & 20 & 2 & 40 & 0 & 1.20275 & 2.29 \\
\hline 2 & 3 & 35 & 5 & 60 & 2 & 2.06186 & 2.30 \\
\hline 3 & 3 & 55 & 8 & 80 & 4 & 1.11684 & 2.18 \\
\hline 4 & 3 & 75 & 11 & 100 & 6 & 1.20275 & 2.63 \\
\hline 5 & 12 & 20 & 5 & 80 & 6 & 2.83505 & 3.46 \\
\hline 6 & 12 & 35 & 2 & 100 & 4 & 6.18557 & 4.21 \\
\hline 7 & 12 & 55 & 11 & 40 & 2 & 3.86598 & 4.83 \\
\hline 8 & 12 & 75 & 8 & 60 & 0 & 2.4055 & 5.68 \\
\hline 9 & 21 & 20 & 8 & 100 & 2 & 18.4708 & 6.70 \\
\hline 10 & 21 & 35 & 11 & 80 & 0 & 15.6357 & 6.95 \\
\hline 11 & 21 & 55 & 2 & 60 & 6 & 12.9725 & 6.60 \\
\hline 12 & 21 & 75 & 5 & 40 & 4 & 13.6598 & 6.52 \\
\hline 13 & 30 & 20 & 11 & 60 & 4 & 18.299 & 7.22 \\
\hline 14 & 30 & 35 & 8 & 40 & 6 & 17.5258 & 7.12 \\
\hline 15 & 30 & 55 & 5 & 100 & 0 & 17.268 & 7.53 \\
\hline 16 & 30 & 75 & 2 & 80 & 2 & 14.1753 & 7.31 \\
\hline
\end{tabular}

\section{Regression Analysis}

The calculated mathematical regression equation of MRR for material EN31 is as follows.

MRR $=-1.43+0.640$ Ip -0.0473 Ton +0.142 Toff + $0.0233 \mathrm{~V}-0.066$ Conc

The calculated mathematical regression equation of $\mathrm{Ra}$ for material EN31 is as below.

$\mathrm{Ra}=1.73+0.189 \mathrm{Ip}+0.0107$ Ton +0.0461 Toff -0.00121 V - 0.112 Conc

\section{Grey Relational Analysis}

This approach converts a multiple- response- process optimization problem into a single response optimization situation.

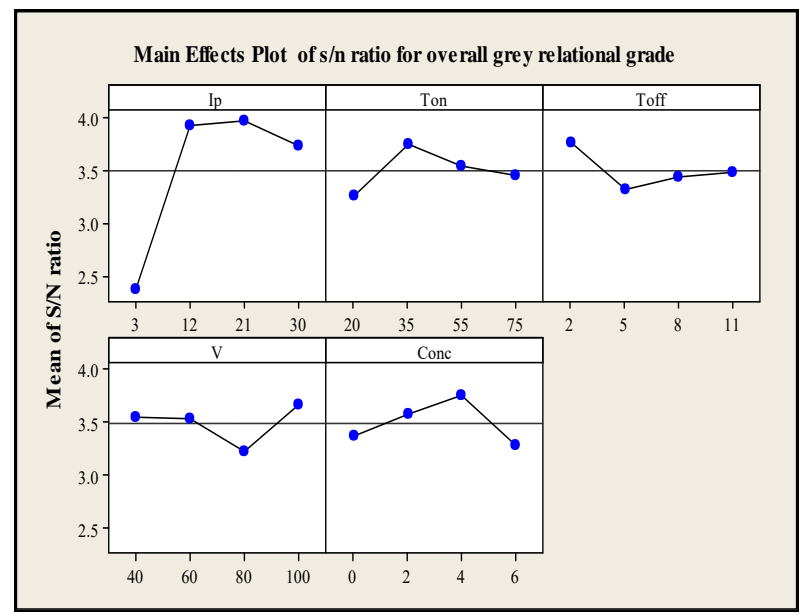

Graph 1: S/N Ratio plot of overall grey relational grade

With the help of the graph 1, optimal parametric combination has been determined. The optimal factor setting becomes $\mathrm{Ip}_{3}, \operatorname{Ton}_{2}, \operatorname{Toff}_{1}, \mathrm{~V}_{4}, \mathrm{C}_{3}$

\section{Confirmation}

Table 2: Results of confirmatory experiment

\begin{tabular}{|c|c|c|}
\hline \multirow{2}{*}{} & \multicolumn{2}{|c|}{ Optimal setting } \\
\cline { 2 - 3 } & Prediction & Experiment \\
\hline Level of factors & $\mathrm{Ip}_{3}$, Ton $_{2,}$ Toff $_{1,} \mathrm{~V}_{4}, \mathrm{C}_{3}$ & $\mathrm{Ip}_{3}$, Ton $_{2,}$ Toff $_{1,} \mathrm{~V}_{4}, \mathrm{C}_{3}$ \\
\hline S/N ratio & 3.8433 & 3.2195 \\
\hline $\begin{array}{c}\text { Overall grey } \\
\text { relational grade }\end{array}$ & 1.55657 & 1.4487 \\
\hline
\end{tabular}

\section{Conclusion}

The material removal of the EDM process is rather low, especially in the case of EDM where the total volume of a cavity has to be removed. If the EDM is operated at the optimum setting of electrical parameters then this drawback can be minimized.

While machining the material EN31, the industrialist can directly use the optimum values so that the material removal rate will be maximum and Ra value will be minimum.

The common optimum values for both MRR and Ra can be easily obtained by the use of grey relational analysis method.

\section{References}

[1] H.K.Kansal , S.Singh and Pradeepkumar, "Effect of Silicon Powder Mixed EDM on Machining Rate of AISI D2 Die Steel",Journal of Manufacturing Processes Vol. 9/No. 12007.

[2] M. Kiyak and O. Cakir, " Examination of machining parameters on surface roughness in EDM of tool steel", Journal of Materials Processing Technology 191 (2007) 141-144.

[3] Anirban Bhattacharya \& Ajay Batish\&Gurmail Singh $\& V$. K. Singla, Optimal parameter settings for rough and finish machining of die steels in powder-mixed EDM, Int J AdvManufTechnol (2012) 61:537-548.

[4] Katsushi Furutani\&Hiromichi Sato \& Masayuki Suzuki, Influence of electrical conditions on performance of 


\section{International Journal of Science and Research (IJSR) \\ ISSN (Online): 2319-7064}

Index Copernicus Value (2013): 6.14 | Impact Factor (2015): 6.391

electrical discharge machining with powder suspended in working oil for titanium carbide deposition process; Int J AdvManufTechnol (2009) 40:1093-1101.

[5] Paulo Peças\&Elsa Henriques, Effect of the powder concentration and dielectric flow in the surface morphology in electrical discharge machining with powder-mixed dielectric (PMD-EDM), Int $\mathrm{J}$ AdvManufTechnol (2008) 37:1120-1132.

[6] Promod K. Patowari\&ParthaSaha\&Prasanta K. Mishra, Taguchi analysis of surface modification technique using $\mathrm{W}-\mathrm{Cu}$ powder metallurgy sintered tools in EDM and characterization of the deposited layer; Int $\mathrm{J}$ AdvManufTechnol (2011) 54:593-604.

[7] KEESAM SHIN, DONGSUP CHUNG, and SUNGHAK LEE, „The Effect of Consolidation Temperature on Microstructure and Mechanical Properties in Powder Metallurgy-Processed 2XXX Aluminum Alloy Composites Reinforced with $\mathrm{SiC}$ Particulates; Center for Advanced Aerospace Materials, Pohang University of Science and Technology, Pohang, 790- 784 Korea.

[8] Y.-F. Tzeng and C.-Y.Lee, Effects of Powder Characteristics on Electro discharge Machining Efficiency;Int J AdvManufTechnol (2001) 17:586-592.

[9] Han-Ming Chow, Lieh-Dai Yang, Ching-Tien Lin, Yuan-Feng Chen, "The use of SiC powder in water as dielectric for micro-slit EDM machining", journal of materials processing technology $195\left(\begin{array}{llll}2 & 0 & 0 & 8\end{array}\right)$ 160170.

[10] FarhadKolahan Mohammad Bironro, G.H., 2007. A HEURISTIC ALGORITHM FOR THE OPTIMAZATION OF POWDER-MIXED EDM PARAMETERS FOR TI-CO ALLOYS,Proceedings of the Third International Conference on Modeling, Simulation and Applied Optimization ,Sharjah, U.A.E January 20-22 2009.

[11] Kuang-Yuan Kung \&Jenn-TsongHorng\&Ko-Ta Chiang, "Material removal rate and electrode wear ratio study on the powder mixed electrical discharge machining of cobalt-bonded tungsten carbide", Int J AdvManufTechnol (2009) 40:95-104 